\title{
Historical Traces of Austrian Mathematicians in the First Half of the 20th Century
}

Robert Frühstückl (University of Vienna, Austria)

The aim of this paper is to provide a selective overview of available historical records and archival material in relation to Austrian mathematicians. I am limiting the scope of this exposition both geographically and historically, focusing on the cities of Vienna and Innsbruck in roughly the first half of the 20th century. Naturally, this does not imply that these are the only places in Austria where historians or mathematicians could find material of interest, but is simply due to having to choose concrete examples, as an exhaustive coverage would be impossible in this context.

Not long ago, as a start to the archive series in the EMS Newsletter, David Rowe reported on the extensive collection of German mathematicians' papers at the Göttingen State and University Library (SUB), where a Central Archive for German Mathematics Bequests was established in a joint project with the German Mathematical Society (DMV). ${ }^{1}$ Unfortunately, a similar arrangement does not exist in Austria. To my knowledge, there are only a small number of collections that are open to researchers, some of which will be presented in the following.

I will begin with Wolfgang Gröbner's (1899-1980) papers, stored at the Archives of the University of Innsbruck. This collection is quite extensive and thus provides a unique opportunity for studying various aspects of Gröbner's work as a mathematician, such as his per-

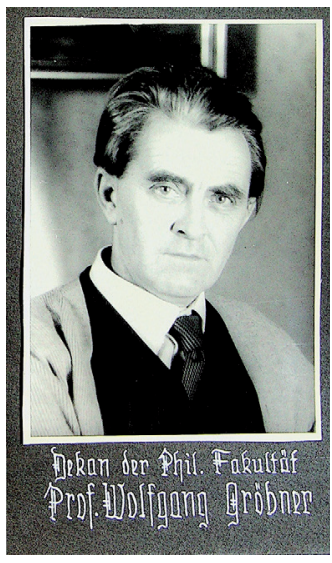

Wolfgang Gröbner as dean of the Faculty of Philosophy of the University of Innsbruck, 1950. (Innsbruck University Archive)

\footnotetext{
1 Rowe 2016.

2 Sigmund 2015.
}

famous for his work in complex analysis, whereas Furtwängler is remembered mostly for his work in algebraic number theory. Gröbner received his doctorate from the University of Vienna in 1932 under the supervision of Furtwängler.

After his studies in Vienna and a study visit to Göttingen, Gröbner's career took him to Rome, and only briefly back to the University of Vienna. In Rome, Gröbner was a member of the Institute for Applied Mathematics under its director Mauro Picone. ${ }^{3}$ Probably at this time, Gröbner began several long-lasting acquaintances with Italian mathematicians, which can be reconstructed on the basis of his correspondence. He was also handpicked to lead a research group on industrial mathematics in 1942, which was part of a bigger aviation research facility funded by the NS regime during the Second World War, before receiving a position at the University of Innsbruck in 1947 , where he was active until $1970 .^{4}$

Gröbner's papers cover a wealth of material, including not only correspondence from about the 1930s onwards until well into the 1970s, but also various manuscripts of his mathematical work and teaching material, as well as items from Gröbner's personal library. They include not only mathematical literature but also works of philosophy, for example William James' Pragmatism and several volumes by Robert Reininger. Considering this apparent interest in philosophy, it is not surprising that the collection also contains manuscripts of Gröbner's own philosophical writings and lectures, of which he had published a significant number since the 1960s. There are also several documents relating to his infamous non-mathematical seminar course on Grenzprobleme (boundary problems) at the University of Innsbruck, which was intended as a critical reflection on the epistemology of knowledge claims in theology and which raised considerable controversy among members of the theological faculty in Innsbruck. $^{5}$

Overall, the collection consists of 16 boxes, among them six boxes exclusively containing correspondence with a wide range of mathematicians especially from Germany and Italy. The papers are grouped according to their years of origin and (partially) alphabetically in the history of Austrian mathematics and both substantially shaped the Mathematical Seminar at the University of Vienna well into the $1930 \mathrm{~s}^{2}$ Wirtinger is

\footnotetext{
3 Epple et al. 2005.

4 Goller und Oberkofler 1993. On Gröbner's work during WW2 see esp. Epple et al. 2005.

5 A description of Gröbner's quarrels with the theological faculty at the University of Innsbruck is given (in German) by Goller und Oberkofler 1993.
} 
ordered. In addition to the wide range of correspondents, it is also the sheer quantity of papers available that makes the collection special. I did not undertake to count the entire material, but the first box of the six containing Gröbner's correspondence alone contains several hundred sheets of paper.

It is perhaps interesting to note that one of the oldest items of this correspondence is a letter the young Gröbner sent to Emmy Noether in 1932, right after he had returned from a study visit to the University of Göttingen, in which he summarised and reported on his latest work.
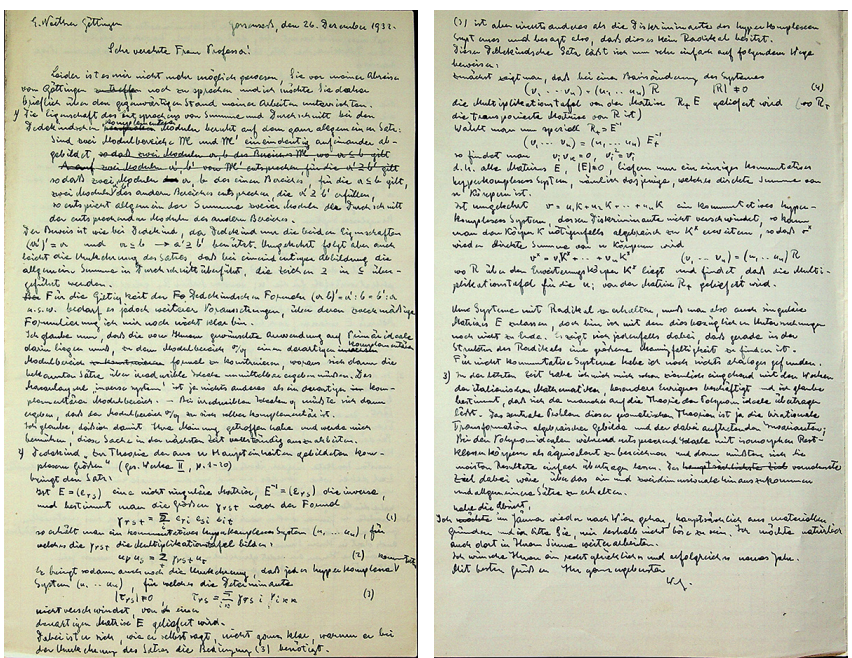

Gröbner's letter to Emmy Noether from December 26, 1932. (Innsbruck University Archive)

At that time, Gröbner was interested in algebraic geometry and just about to develop his own views on ideal theory. Unfortunately, the collection does not contain Noether's reply, if there was one.

The oldest items in the collection also include handwritten excerpts from works by Noether, but also Richard Dedekind and Bartel van der Waerden, which give us a glimpse into the scope of Gröbner's studies in the early 1930s.

His letter to Noether points to an interesting general aspect of the history of Austrian mathematics from the late 19th to the first decades of the 20th century: Gröbner was not the only student from Vienna who was awarded the opportunity to visit Göttingen. From about the second half of the 19th century on, it was established practice to provide excellent doctoral students with grants that enabled them to go to Göttingen, Berlin, Milan or Paris for some time to continue their studies at one of the most important centres for mathematical research in Europe. ${ }^{6}$ As a matter of fact, Wilhelm Wirtinger, for example, visited Berlin and Göttingen after having received his doctorate from the University of Vienna in $1887 . .^{7}$ Unfortunately this tradition of cooperation between Vienna and Göttingen seems to have declined during the 1930s for reasons which are not entirely clear, but might have been due to the increasing political ten-

\footnotetext{
6 Binder 2003.

7 Cf. Einhorn 1985, pp. 7-8.
}

sions between Austria and National Socialist Germany at that time.

As already indicated, Gröbner corresponded widely with several important and prominent figures in the history of mathematics. Among these are Wilhelm Blaschke, Bartel van der Waerden, Gerrit Bol, Helmut Hasse, Gerhard Gentzen, Oskar Perron and Ludwig Prandtl, to name just a few.

Because Gröbner was fluent in Italian, he was destined to take on the role of an intermediary between German and Italian mathematicians, translating not only between languages but apparently also between research cultures. ${ }^{8}$ Thus, the collection also contains letters written in Italian that Gröbner exchanged with Mauro Picone and Francesco Severi.

This particular position as well as his stay at Picone's Institute for Applied Mathematics in Rome was very likely one of the reasons that made Gröbner a prime candidate for the organisation of an applied mathematics institute, the so-called Arbeitsgruppe für Industriemathematik (Working Group for Industrial Mathematics) at the aeronautical research facility in Braunschweig in 1942 (see above).

In addition to the correspondence, the collection certainly deserves attention for the numerous manuscripts and offprints relating to one of Gröbner's greater research projects in Innsbruck after the war, which is the development of the method of Lie-series for the numerical solution to differential equations. Of particular interest in this regard could also be that Gröbner received funding for this research from NASA and other US government institutions as well as private companies, such as General Electric. This switching between work in pure and applied mathematics is certainly one of the many interesting features of Gröbner's career.

Just in passing I want to mention the papers of another Austrian mathematician who held a position at the University of Innsbruck: Leopold Vietoris (1891-2002).

Vietoris received his doctorate from the University of Vienna, where Gustav von Escherich and Wilhelm Wirtinger were his supervisors. In 1925, Vietoris was awarded a grant by the Rockefeller foundation ${ }^{9}$ and went to Amsterdam to study with L.E.J. Brouwer. After his return and some intermediate career steps, Vietoris finally settled at the University of Innsbruck in 1930. Today Vietoris is known for, among other things, his contri-

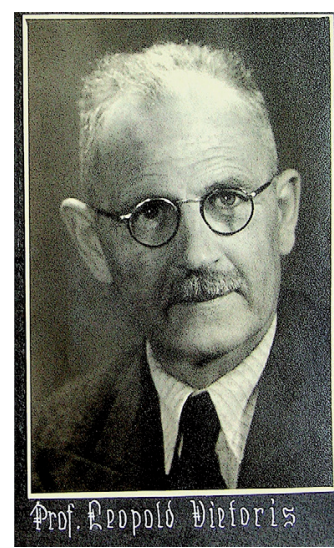

Leopold Vietoris as dean of the Faculty of Philosophy of the University of Innsbruck, 1947. (Innsbruck University Archive)

8 As pointed out to the author by Peter Goller.

9 The Rockefeller Foundation funded several European mathematicians, esp. during the 1920s. For a historical analysis of its activities within the field of mathematics see SiegmundSchultze 2001. 
butions to the field of topology as well as his work on probability theory, which he only took up in the 1980s. ${ }^{10}$ Together with Wolfgang Gröbner, who would join him after the war, they would both shape the Institute of Mathematics at the University of Innsbruck in the second half of the 20th century.

Leopold Vietoris' papers contain his correspondence from 1945 to 2001, which comes alphabetically ordered in several boxes, as well as scientific manuscripts, several offprints and teaching material on differential geometry, logic and set theory, topology and analytic geometry, among others. One of the highlights of the collection is surely a letter to Felix Hausdorff; the collection also contains Vietoris' personal copy of Hausdorff's Grundzüge der Mengenlehre, first published in $1914 .{ }^{11}$

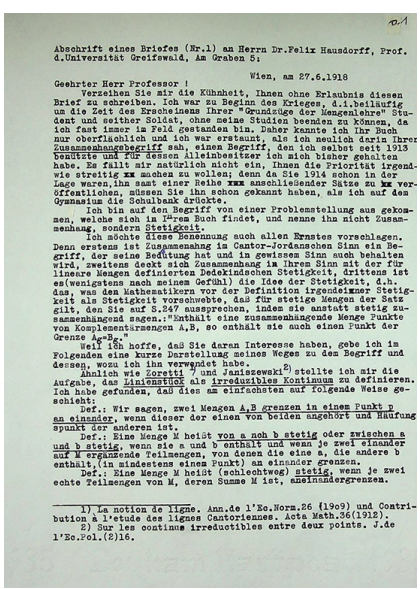

First page of a letter from Vietoris to Felix Hausdorff, June 27, 1918. (Innsbruck University Archive)
The material can be consulted at the University Archives, located in the University's main building near the city centre of Innsbruck. The staff of the Archive, especially its director Peter Goller, are very supportive and strive to facilitate a pleasant working experience. It should also be mentioned that Peter Goller, because of his rich and comprehensive knowledge of the history of the University of Innsbruck, can provide a good deal of additional helpful and illuminating information, missing links and advice for research on the Gröbner and Vietoris collections.

The history of mathematics in Austria is naturally closely connected to the history of the University of Vienna, which celebrated its 650th anniversary in 2015 and is thus one of the oldest academic institutions in the German-speaking countries. The University of Vienna was a stage in the career paths of many Austrian mathematicians and the Mathematical Seminar functioned as the central point of the discipline, not only because the Österreichische Mathematische Gesellschaft (Austrian Mathematical Society) was founded there but also because the Monatshefte für Mathematik und Physik were edited and published in Vienna. Unfortunately though, collections as extensive as the Gröbner and Vietoris bequests are not available at the University Archives. Scholars can, however, turn to several other historical sources on Austrian mathematicians. The archives of the University of Vienna and the Technical University of Vienna contain staff records of mathematicians who either held a position at

\footnotetext{
10 Reitberger 2002.

11 A reproduction of Vietoris' letter as well as Hausdorff's reply is available online at the website of the Archives of the University of Innsbruck: https://www.uibk.ac.at/universitaetsarchiv/copy_of_dokumente-aus-dem-universitaetsarchiv/.
}

the faculty or obtained their venia legendi (awarded after successfully completing the habilitation) there. Although the amount of material contained in these records does vary, all in all they contain a good deal of information on such distinguished figures in the history of Austrian mathematics as Wilhelm Wirtinger, Philipp Furtwängler, Hans Hahn, Kurt Gödel, Karl Menger, Eduard Helly, Alfred Tauber and Johann Radon, to name just a few.

The history of mathematics at the University of Vienna is of particular interest not only to practitioners of the field but to anyone interested in the history of science, culture and society in the turbulent decades following the fin-de-siècle.

Strikingly, for some time during the first half of the 20th century, mathematicians and philosophers came into closer contact with one another in Vienna. Although this is by no means an exclusive characteristic of the Viennese tradition - after all, the developments in mathematical logic and set theory as well as the well-known foundational crisis in mathematics after the First World War brought with them an increase in philosophical interest in mathematics almost everywhere in Europe - Vienna around the 1920s was the place where the Vienna Circle, a discussion group of philosophers, physicists and mathematicians, was formed. The outcome of the work of this group, the philosophical position of Logical Empiricism, became one of the most influential schools of philosophy after its founders emigrated to the United States following the political turmoil of the 1930s in Europe. One of the founding members of the Vienna Circle was the mathematician Hans Hahn (1879-1934), who held one of the three chairs of mathematics at the University of Vienna at that time, his colleagues being the aforementioned Wilhelm Wirtinger and Philipp Furtwängler.

Hahn played a quintessential role in the history of science and mathematics as he made important contributions to modern analysis and is counted among the creators of functional analysis. ${ }^{12}$ But Hahn was not only a distinguished mathematician and promoter of a scientific world conception through the founding of the Vienna Circle, but also teacher and sponsor of

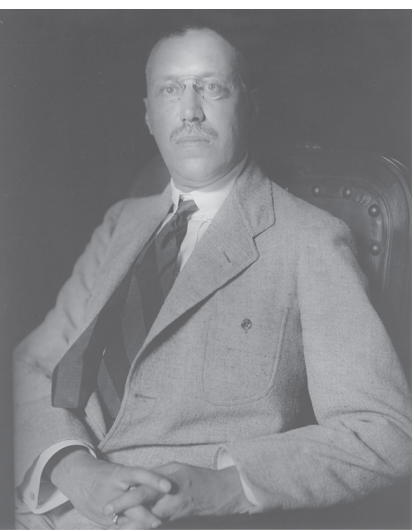

Hans Hahn, date unkown. (Vienna University Archive, 106.I.43.) two exceptionally talented students in the 1920s: Karl Menger (1902-1985) and Kurt Gödel (1906-1978).

The Archives of the University of Vienna contain Gödel's staff records, which allow some insight into the rather complex process of his emigration to the United States after the Nazis' seizure of power in Austria. ${ }^{13}$

\footnotetext{
12 Sigmund 2015.

13 Vide Sigmund et al. 2006.
} 
However, in the following I want to focus on Karl Menger, since in addition to his staff records, the University Archives also hold a few of his personal papers. This collection was originally given to the Technical University of Vienna by Menger's daughter Rosemarie MengerGilmore, but was transferred to the University of Vienna Archives in 2012, where it is now stored. As already indicated, these records do not contain a very large amount of material but there are two items which should be of general interest.

Menger is an important figure in the history of Austrian mathematics, as well as in the broader cultural history of Vienna. He was the son of the economist Carl Menger, who is famous for his groundbreaking work in economics, especially on the development of the theory of marginal utility. He also worked on the methodology of economics as a branch of the theoretical social sciences, where he developed an account that would emphasise its dissociation from the so-called historical school of economics prevailing at that time. The works of Carl Menger are also widely regarded as essential in the formation of the Austrian school of economics.

His son Karl studied mathematics, physics and philosophy at the University of Vienna and received his doctorate in mathematics in 1924 under the supervision of Hans Hahn, who seems to have had considerable impact on the young Menger. In his Reminiscences of the Vienna Circle and the Mathematical Colloquium, Menger recalls his first impressions of attending a seminar with Hahn:

In March 1921, just after Hahn's arrival in Vienna, I read a notice that he would conduct a two-hour advanced seminar every Wednesday during spring semester, entitled Neueres über den Kurvenbegriff (News about the concept of curves). [...] Hahn went right to the heart of the problem. Everyone, he began, has an intuitive idea of curves [...]. But anyone who would try to make that idea precise, Hahn said, would encounter great difficulties. ${ }^{14}$

Hahn later generalised this observation of the difficulties involved in specifying the intuitive notion of curve to an extensive criticism of the concept of intuition in the epistemology of mathematics. His paper titled Die Krise der Anschauung (The Crisis of Intuition) was first published in a series entitled Krise und Neuaufbau in den exakten Wissenschaften (Crisis and Rebuilding of the Exact Sciences) co-edited by Hahn, Menger, the physicist Hans Thirring and chemist Hermann Mark. ${ }^{15}$ Remarks Hahn had made more than ten years prior to this extensive discussion seem to have had a stunning effect on Menger:

I was completely enthralled; and when after that short introduction, Hahn set out to develop the principal tools used in those earlier attempts - the basic concepts of Cantor's point set theory, all totally new to me - I

\footnotetext{
${ }^{14}$ Menger 1994, pp. 38-39.

${ }^{15}$ Mark et al. 1933. For a reprint of Hahn's contribution see Hahn 1980.
}

followed with the utmost attention. [...] I left the seminar room in a daze. Like everyone else, I used the word 'curve' and had an intuitive idea of curves - mental pictures associated with the term. Should I not be able spell out [sic!] articulately how I used the word and to describe clearly what I saw? ${ }^{16}$

This far-reaching experience set the stage for Menger's work on the theory of dimension and curves, which he began immediately after having encountered the problem in Hahn's seminar. A typescript of Menger's work on the definition of the concepts of curve and dimension from 1921 is part of his personal papers held at the Archives of the University of Vienna. It is the very same document that Menger himself deposited at the Austrian Academy of Sciences in 1923. The collection also contains a notification concerning the reopening of the sealed documents eight years later in 1929.

Knowing Hans Hahn was also instrumental in getting Menger to attend the weekly meetings of the Vienna Circle, where especially the philosopher-physicist Moritz Schlick and the philosopher-logician Rudolf Carnap expressed interest in discussing Menger's work on curves and dimension. His frequent participation in these meetings would soon lead to him distancing himself from this group, although he never broke entirely with the Circle. Instead he remained at its periphery and started his own discussion group, the Mathematisches Kolloquium (Mathematical Colloquium), whose results were published in a separate periodical called the Ergebnisse eines Mathematischen Kolloqiums (Results of a Mathematical Colloquium), which was co-edited by Kurt Gödel, who has already been mentioned, and Georg Nöbeling, who studied with Menger and received his doctorate under his supervision in $1931 .{ }^{17}$

Mathematicians interested in logic and model theory may find it interesting that it was also Menger who invited Alfred Tarski to Vienna to participate in the Mathematische Kolloquium in the late 1920s. But the scope of mathematical fields discussed in the Kolloquium was much broader. Regular participants included Abraham Wald, who made significant contributions to mathematical statistics and econometrics, and Olga Taussky-Todd who, after receiving her doctorate from Philipp Furtwängler, gained an excellent reputation for her work in algebraic number theory. The example of Wald and Taussky-Todd also shows that Menger's role in organising the Kolloquium did not stop at providing a platform for mathematical discussion but also involved active financial support. Together with Hahn, Menger organised a series of scientific lectures for the general public in

\footnotetext{
${ }^{16}$ Menger 1994, pp. 39-41.

17 On the history of Menger's relation to the Vienna Circle and the formation of the Mathematical Colloquium see Stadler 2015a, pp. 201ff (for an English version see Stadler 2015b). The papers of the Ergebnisse eines Mathematischen Kolloquiums were edited and published by Egbert Dierker and Karl Sigmund in a comprehensive volume, see Dierker und Sigmund 1998
} 
Vienna, which received much attention at that time. The money collected from the entrance fees to these talks was used to support scholars like Taussky-Todd and Wald. ${ }^{18}$

However, before all that took place, Menger left Vienna in 1925 to go to Amsterdam and continue his work with L.E.J. Brouwer, having been awarded funding from the Rockefeller Foundation. Just about a year later, Menger earned his habilitation with a work on the theory of curves. Although the Amsterdam period was apparently stimulating and productive for Menger, he got into a serious conflict with Brouwer just a short time later, after Brouwer had raised grave accusations against Menger over the issue of priority in the development of the theory of dimension. The dispute that followed lasted several years and in 1930, Menger saw himself forced to directly reply to Brouwer's accusations in volume 37 of the Monatshefte für Mathematik und Physik, ${ }^{19}$ the principal journal of Austrian mathematics founded in 1890 by Gustav von Escherich and Emil Weyr. Menger's personal papers at the University Archives also contain traces of this dispute, which take the form of a manuscript detailing different versions of a reply to Brouwer from about the late 1920s.

After the quarrels with Brouwer, Menger left Amsteram for good and returned to Vienna to take over the chair for geometry at the University that had previously been held by Kurt Reidemeister. In his Reminiscences of the Vienna Circle and the Mathematical Colloquium, Menger recalls: "The Vienna of 1927 had again become a highly interesting and intellectually lively city." 20

These words stand witness for a vibrant and creative intellectual atmosphere in Vienna, even in the late 1920s - an atmosphere that, already frail at that time, would soon collapse as the city entered in 1930 into the new dec-

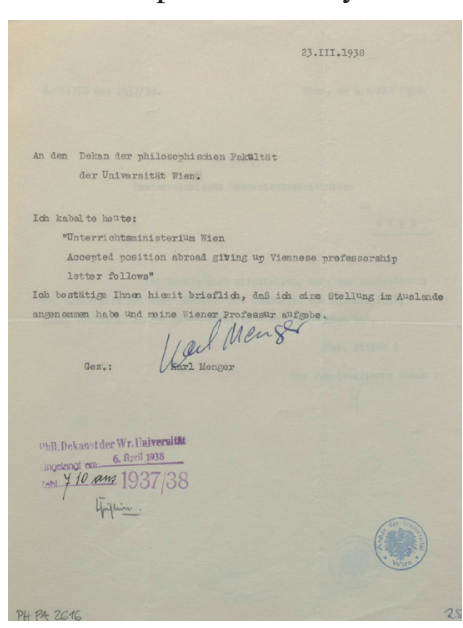

Menger's letter of resignation to the dean of the Faculty of Philosophy of the University of Vienna, March 23, 1938. (Vienna University Archive, PH PA 2616) ade which would see two regime changes in Austria. Disaffected by the increasingly repressive climate and the murder of Moritz Schlick in 1936, Menger decided to leave Austria for the United States and started teaching at Notre Dame in 1937. When the Nazis seized power in Austria in 1938, Menger formally resigned from his position at the University of Vienna. The ministerial decree effectuating his dismissal followed three months later.

\footnotetext{
${ }^{19}$ According to Einhorn, based on an oral report from the Austrian mathematician Edmund Hlawka in Einhorn 1985, p. 184. Vide also the section on Olga Taussky-Todd in Sigmund 2001

${ }^{19}$ Menger 1930.

${ }^{20}$ Menger 1994, p. 9.
}

Menger was not the only mathematician who lost his position because of the racist political agenda of the new regime. In addition to Menger, eminent mathematicians such as Kurt Gödel, Eduard Helly and Alfred Tauber were also affected. ${ }^{21}$

The fate of Alfred Tauber (1866-1942) is particularly tragic as he was not able to emigrate after 1938 and was subsequently deported to the Theresienstadt concentration camp, where he died in $1942 .{ }^{22}$

Tauber had made significant contributions to analysis: the concept of Tauberian theorems in particular originates in his work. Nevertheless, he had been unable to find a suitable academic position in Vienna, and his main teaching activity was the introductory courses in insurance mathematics. His principal income came from a position as a mathematician in an Austrian insurance company, a fate he shared with Eduard Helly. 23

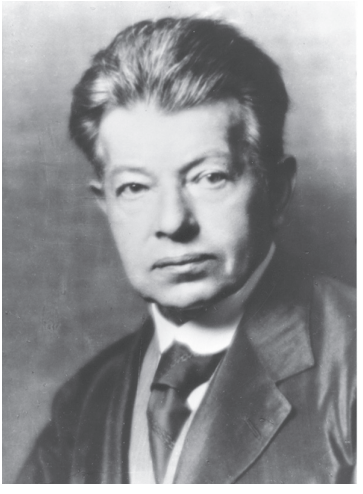

Alfred Tauber, date unknown. (Vienna University Archive, 106.I.91)
Karl Menger did not return to Europe after 1945, although this option was considered by the University of Vienna after the war. However, it seems that several objections were raised against the suggestions to reinstall Menger in his position. One of them was voiced by natural scientists - especially in the field of mineralogy - on the grounds that the lectures in geometry should be taught as "close to intuition" as possible. ${ }^{24}$ This was just 25 years after Menger's efforts to specify the intuitive notion of curve were initiated in Hahn's seminar.

Additional material on Menger's professional biography can be found in his staff records at the University Archives.

Finally, I want to point out that in addition to archival material there is also a significant body of published literature which is an excellent source for the history of Austrian mathematics. Thus I would like to briefly turn the reader's attention to the aforementioned Monatshefte für Mathematik und Physik, which were published until 1944 and functioned as the main communication platform for the discipline in Austria. The papers in this journal provide a unique perspective on the development of mathematics in Austria as well as its intellectual community. The Monatshefte continued to appear after the war and are still published today under the title Monatshefte für Mathematik. All volumes of the Monatshefte are fully digitized and can thus be easily explored through the respective databases (to which university libraries will usually provide access). In addition to original papers, the Monatshefte also contained extensive literature reviews, which provide a glimpse into the exchange and reception

\footnotetext{
${ }^{21}$ Reiter 2001.

22 Binder 1984, Sigmund 2015.

${ }^{23}$ Sigmund 2004.

${ }^{24}$ Cf. Einhorn 1985, pp. 185-186.
} 
of ideas within the broader intellectual network of which Austria was just one part. The inventory of the University Archives can be searched through an online Archive Information System. ${ }^{25}$ However, this only provides an overview of the items since the online system is not complete. Additional search tools are available on site in the archive's reading room. Also, the staff at the University Archives are very helpful in handling research requests and provide excellent and friendly support to visitors.

\section{Acknowledgements}

I am grateful to Peter Goller and Thomas Maisel for the permission to use the pictures published in this article.

\section{References}

Binder, Christa (1984): „Alfred Tauber (1866-1942) - Ein österreichischer Mathematiker", in: Jahrbuch Überblicke Mathematik, pp. $151-166$

- (2003): „Vor 100 Jahren: Mathematik in Wien“, in: Internationale Mathematische Nachrichten 193, pp. 1-20.

Dierker, Egbert; Sigmund, Karl (eds.) (1998): Karl Menger. Ergebnisse eines Mathematischen Kolloquiums. Vienna: Springer.

Einhorn, Rudolf (1985): Vertreter der Mathematik und Geometrie an den Wiener Hochschulen 1900-1940. 2 vols. Wien: Verband der wissenschaftlichen Gesellschaften Österreichs (Dissertationen der Technischen Universität Wien, 43/1-2).

Epple, Moritz; Karachalios, Andreas; Remmert, Volker R. (2005): “Aerodynamics and Mathematics in National Socialist Germany and Fascist Italy: A Comparison of Research Institutes”, in: Osiris 20, pp. 131-158.

Goller, Peter; Oberkofler, Gerhard (1993): „...daß auf der Universität für die Lehre, die dort vertreten wird, wirkliche Gründe gegeben werden! Wolfgang Gröbner (1899-1980), Mathematiker und Freidenker", in: Zentralbibliothek für Physik in Wien (ed.): Österreichische Mathematik und Physik. Wolfgang Gröbner, Richard von Mises, Wolfgang Pauli. Wien:Zentralbibliothek für Physik, pp.9-49.

Hahn, Hans (1980): Empiricism, Logic and Mathematics. Philosophical Papers. Edited by Brian McGuinness. Dordrecht: Springer (Vienna Circle collection, 13).

Mark, Herman F.; Thirring, Hans; Hahn, Hans; Nöbeling, Georg; Menger, Karl (1933): Krise und Neuaufbau in den exakten Wissenschaften: fünf Wiener Vorträge. Leipzig, Wien: Deuticke.

Menger, Karl (1930): „Antwort auf eine Note von Brouwer“, in: Monatshefte für Mathematik und Physik 37, pp. 175-182.

Menger, Karl (1994): Reminiscences of the Vienna Circle and the Mathematical Colloquium. Edited by Louise Golland, Brian McGuinness and Abe Sklar. Dordrecht, Boston: Kluwer Academic Publishers (Vienna Circle collection, 20).

Reitberger, Heinrich (2002): „Leopold Vietoris zum Gedenken (4.6.1891 - 9.4. 2002)", in: Internationale Mathematische Nachrichten 191, pp. 1-16.

Reiter, Wolfgang L. (2001): „Die Vertreibung der jüdischen Intelligenz: Verdopplung eines Verlustes - 1938/1945“, in: Internationale Mathematische Nachrichten 187, pp.1-20.

Rowe, David E. (2016): "Göttingen's SUB as Repository for the Papers of Distinguished Mathematicians", in: Newsletter of the European Mathematical Society Issue 101, pp. 39-44.

Siegmund-Schultze, Reinhard (2001): Rockefeller and the Internationalization of Mathematics Between the Two World Wars. Document and Studies for the Social History of Mathematics in the 20th Century. Basel: Birkhäuser (Science Networks. Historical Studies, 25).
Sigmund, Karl (2001): „Kühler Abschied von Europa“-Wien 1938 und der Exodus der Mathematik. Arkadenhof der Universität Wien 17. September - 20. Oktober 2001. Ausstellungskatalog. Unter Mitarbeit von Österreichische Mathematische Gesellschaft. Wien: Österreichische Mathematische Gesellschaft.

- (2004): "Failing Phoenix: Tauber, Helly, and Viennese Life Insurance", in: The Mathematical Intelligencer 26 (2), pp. 21-33.

- (2015): „Mathematik an der Universität Wien“, in: Karl Anton Fröschl, Gerd B. Müller, Thomas Olechowski und Brigitta SchmidtLauber (eds.): Reflexive Innensichten aus der Universität. Disziplinengeschichten zwischen Wissenschaft, Gesellschaft und Politik. Göttingen: V \& R Unipress, Vienna Univ. Press (650 Jahre Universität Wien - Aufbruch ins neue Jahrhundert, 4), pp. 459-469.

Sigmund, Karl; Dawson, Jim; Mühlberger, Kurt (2006): The Gödel Album. Wiesbaden: Vieweg.

Stadler, Friedrich (2015a): Der Wiener Kreis. Ursprung, Entwicklung und Wirkung des Logischen Empirismus im Kontext. Wien: Springer.

- (2015b): The Vienna Circle. Studies in the Origins, Development, and Influence of Logical Empiricism. Cham: Springer.

\section{Appendix}

Selection of personal papers at the Archives of the University of Innsbruck (UAI)

- Gröbner, Wolfgang

- Vietoris, Leopold

Selection of staff records at the Archive of the University of Vienna (UAW)

- Furtwängler, Philipp

- Gödel, Kurt

- Gröbner, Wolfgang

- Hahn, Hans

- Helly, Eduard

- Menger, Karl

- Radon, Johann

- Tauber, Alfred

- Wirtinger, Wilhelm

Additional Material at the Archive of the University of Vienna - Menger, Karl, Nachlassfragment

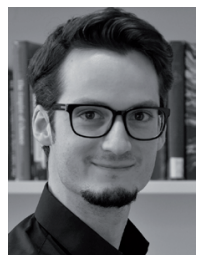

Robert Frühstückl recently obtained his doctorate in the history of science from the University of Vienna with his work on mathematical institutions in Vienna between 1930 and 1945. His studies were based on the history and philosophy of science esp. the Vienna Circle and the history of science in National Socialism. In 2016 he was visiting pre-doctoral research fellow at the Max-Planck-Institute for the History of Science in Berlin.

${ }^{19}$ https://scopeq.cc.univie.ac.at/Query/suchinfo.aspx 